\title{
Implementing the family-centered care model, parents' satisfaction and experiences in neonatology
}

\author{
Immacolata Dall'Oglio ${ }^{1 *}$, Anna Portanova ${ }^{2}$, Martina Fiori $^{1}$, Orsola Gawronski ${ }^{1}$, Roberta Fida ${ }^{3}$, Antonello Cocchieri ${ }^{4}$, \\ Gennaro Rocco ${ }^{5}$, Emanuela Tiozzo ${ }^{1}$, Jos M Latour ${ }^{6}$, Italian Empathic-N Study Group ${ }^{1}$
}

From XX National Congress of the Italian Society of Neonatology

Rome, Italy. 9-11 October 2014

\section{Background}

The quality of family-centered care (FCC) in Neonatal Intensive Care Unit (NICU) is often assessed through Parental satisfaction (PS). Empathic-N, a validated questionnaire to evaluate PS in NICU, was recently developed in the Netherlands [1].To our knowledge similar instruments have not yet been used in Italy. The aim of this project is to translate the 57-item Empathic-N questionnaire and to develop and adapted Italian version for postNICU (Empathic-SN) taking the Italian cultural adaptation into account, and to test their psychometric validity.

\section{Materials and methods}

The translation process followed a structured method including forward and backward translation [2].

The psychometric validation of both the Empathic-N and the Empathic-SN questionnaires is being performed by administering the questionnaires to parents of newborns discharged from 9 NICUs and post-NICUs across Italy.

Ethical approval is granted by the Bambino Gesù Children's Hospital. Written informed consent forms are collected.

\section{Results}

150 questionnaires from NICU and 150 from post-NICU are being collected. Preliminary analyses showed a positive correlation between the questionnaire items and the overall satisfaction indicators. Reached scores ranged from

\footnotetext{
* Correspondence: immacolata.dalloglio@opbg.net

'Professional Development, Continuing Education and Nursing Research Service-Medical Direction, Bambino Gesù Children's Hospital, IRCCS, Rome, Italy

Full list of author information is available at the end of the article
}

4.1 to 5.9 for the Empathic-N and from 4.2 to 5.7 for the Empathic-SN, on a 1-to-6 Likert scale. Results from Cronbach's alpha coefficients attested the reliability of the scale. Thematic analysis of the open answers identified 385 quotations, coded into seven major themes, expressing parents' experiences. Generally, a good overall parents' satisfaction is showed. Further descriptive statistical analysis will be performed on the complete sample.

\section{Conclusion}

Validity and reliability of the Italian version of the questionnaires assessed by psychometric testing is expected. The Empathic-N and Empathic-SN questionnaires, or their further versions, would constitute important tools to assess the actual quality of FCC in Italian NICUs and post-NICUs and to set the baseline for improvement interventions.

\begin{abstract}
Acknowledgements
The Italian Empathic-N Study Group, was as follows: Luca Di Sarra, Catholic University of Rome; Gina Ancora, Sandra Lazzari, Hospital of Rimini; Marilena Galeazzo, Elisabetta Lolli, University Hospital of Padova; Enrica Lupo, Mariella Frongia, Buzzi Children's Hospital, Milan; Silvia Prunecchi, Meyer Children's Hospital of Florence; Angela Ragni, Bambino Gesù Children's Hospital IRCCS Rome, Rosanna Bruno, Antonella Raimondi, San Carlo Hospital, Potenza; Liliana Vagliano, Serena Rovei, Sant'Anna University Hospital, Turin; Loredana Bonafede, Anna Marotta, San Eugenio Hospital, Rome.

The contribution of the Centre of Excellence for Nursing Scholarship for the funding to this project is acknowledged.
\end{abstract}

\section{Authors' details}

'Professional Development, Continuing Education and Nursing Research Service-Medical Direction, Bambino Gesù Children's Hospital, IRCCS, Rome, Italy. ${ }^{2}$ Department of Medical and Surgical Neonatology, Bambino Gesù Children's Hospital, IRCCS, Rome, Italy. ${ }^{3}$ W\&O Psychology, Department of Psychology, Sapienza University of Rome, Italy. ${ }^{4}$ Catholic University of Rome, Italy. ${ }^{5}$ Centre of Excellence for Nursing Scholarship, Ipasvi Rome Nursing College. ${ }^{6}$ School of Nursing, Plymouth University, Plymouth, UK. 


\section{References}

1. Latour JM, Duivenvoorden HJ, Hazelzet JA, van Goudoever JB: Development and validation of a neonatal intensive care parent satisfaction instrument. Pediatr Crit Care Med 2012, 13:554-559.

2. Wild D, Grove A, Martin M, Eremenco S, McElroy S, Verjee-Lorenz A, Erikson P. ISPOR Task Force for Translation and Cultural Adaptation: Principles of Good Practice for the Translation and Cultural Adaptation Process for Patient-Reported Outcomes (PRO) Measures: Report of the ISPOR Task Force for Translation and Cultural Adaptation. Value Health 2005, 8:94-104.

doi:10.1186/1824-7288-40-S2-A47

Cite this article as: Dall'Oglio et al.: Implementing the family-centered care model, parents' satisfaction and experiences in neonatology. Italian Journal of Pediatrics 2014 40(Suppl 2):A47.

\section{Submit your next manuscript to BioMed Central} and take full advantage of:

- Convenient online submission

- Thorough peer review

- No space constraints or color figure charges

- Immediate publication on acceptance

- Inclusion in PubMed, CAS, Scopus and Google Scholar

- Research which is freely available for redistribution

Submit your manuscript at www.biomedcentral.com/submit
(Ciomed Central 